\title{
The nutritive effect of glucose on the structure and function of jejunal self-emptying blind loops in the rat ${ }^{1}$
}

\author{
H. MENGE, ${ }^{2}$ H. WERNER, H. LORENZ-MEYER, AND E. O. RIECKEN
}

From the Medizinische Universitäts-Klinik, Marburg-an-der-Lahn, West Germany

SUMMARY In an attempt to obtain further information on the influence of the intestinal contents on the development of mucosal structure and function, self-emptying blind loops of rat jejunum were constructed, and the oral end was exteriorized with a stoma to permit infusion of different solutions into the loop. Ringer solution or media containing glucose or galactose was instilled into the loops three times daily for 27 days before functional and structural examination of the loops.

The body weight and food intake of the animals did not differ significantly from one group to another.

Treatment with glucose, but not with galactose or Ringer solution alone, induced a significant increase in the villus height. Disaccharidase but not dipeptidase activity was concomitantly increased. Infusion of glucose or galactose both led to an increase in the transport capacity of the loop, as determined by glucose absorption in vivo.

These results indicate that glucose has a nutritive effect, probably due to its intracellular metabolism, which is responsible for the structural alterations observed. On the other hand, the increase in transport capacity may be attributed to substrate-induced stimulation of the specific monosaccharide transport system in the epithelial cell.

Under physiological conditions, most of the alimentary protein and carbohydrate is absorbed in the jejunum, so that the ileal contents are relatively poor in nutritive material (Borgström, Dahlqvist, Lundh, and Sjövall, 1957). Intestinal resection provides an experimental means of altering the nutritive quality of the intestinal contents at different levels of the gut. It has been shown that different degrees of hypertrophy develop in the remaining intestinal segment, depending on whether proximal or distal resection is performed (Booth, Evans, Menzies, and Street, 1959; Dowling and Booth, 1967). Proximal resection induces a much greater hypertrophy of the distal intestine than occurs in the proximal intestine as a result of distal resection, and is accompanied by a parallel increase in transport capacity measured in vivo. To explain this difference, these authors proposed that the more pronounced alterations in

\footnotetext{
${ }^{1}$ Supported by the Deutsche Forschungsgemeinschaft Ri 136/8 u. 9 ${ }^{2}$ Present address: Hôpital Cantonal Universitaire, Département de Chirurgie Expérimentale, Lausanne

Received for publication 3 April 1975.
}

the distal mucosa are caused by the greater nutritional value of the intestinal contents reaching the ileum after proximal resection. Support for the hypothesis that topical nutrition is important for the intestinal mucosa has been obtained from experiments on intestinal transposition, where ileal loops were transposed above the jejunum, and a similar hypertrophy in the ileal segment developed (Dowling and Booth, 1967). On the other hand, a reversible mucosal atrophy, associated with reduced transport capacity, has been demonstrated in self-emptying blind loops, which have been temporarily excluded from intestinal continuity, and in Thiry-Vella fistulae (Menge, Bloch, Schaumlöffel, and Riecken, 1970; Gleeson, Cullen, and Dowling, 1972; Menge, Bloch, Lorenz-Meyer, and Riecken, 1973).

The present study was undertaken in an attempt to pinpoint the effect of the nutritive quality of the transported and metabolizable sugar, glucose, and that of the transported but poorly metabolized sugar, galactose. The effect of both could be compared and contrasted with that of the calorie-free 
Ringer solution. The mucosae were subjected to morphometric evaluation, enzymological investigations and functional analysis.

\section{Methods}

Female Wistar rats weighing 170-190 g were employed. They were fed ad libitum with ground Altromin rat chow and tap water.

\section{OPERATIVE TECHNIQUE}

A blind loop of proximal jejunum was excluded from intestinal continuity, using the procedure described previously (Menge et al, 1970). At its end, a $5 \mathrm{~mm}$ incision was made in the antimesenteric border, the edges of which were anastomosed to a dacron arterial prothesis $(5 \mathrm{~mm}$ diameter, $1 \mathrm{~cm}$ length). This prothesis was connected by means of a plastic nozzle to a latex tube which passed through the lateral peritoneal wall and was conveyed subcutaneously to the back of the animal, where it was exteriorized by means of an incision in the skin of the back of the neck. The opening of the latex tube was then connected to a second plastic nozzle which was completely surrounded with another dacron prothesis. The latter was carefully fixed with sutures and tissue glue to the surrounding skin to prevent dislocation of the tube during the subsequent weeks. Finally, the peritoneum was closed, and the animals were transferred to individual metabolic cages.

\section{POSTOPERATIVE PROCEDURES}

For the first five days after the operation, the animals were nourished solely with a sugared salt solution. Thereafter, they were fed ground Altromin chow and tap water ad libitum, and the exact consumption on each day was determined, together with the body weight of each animal. From this time on, for the next 27 days, the animals received, three times daily at regular intervals, $3 \mathrm{ml}$ of infusate injected into the blind loop through the latex tube. Two groups of litter mates were used, each having its own control:

\section{Group I}

(a) Experimental rats $(n=9)$, receiving an isotonic glucose $/ \mathrm{NaCl}$ solution, containing $36.5 \mathrm{~g}$ glucose and $3.0 \mathrm{~g} \mathrm{NaCl}$ per litre; (b) control rats $(\mathrm{n}=9)$, receiving Ringer solution

\section{Group II}

(a) Experimental rats $(\mathrm{n}=10)$, receiving an isotonic galactose $/ \mathrm{NaCl}$ solution, containing $36.5 \mathrm{~g}$ galactose and $3.0 \mathrm{~g} \mathrm{NaCl}$ per litre; (b) control rats $(\mathrm{n}=9)$, receiving Ringer solution.
The blind loops were then examined on the 32nd postoperative day.

\section{TRANSPORT STUDIES}

Glucose $(21 \mathrm{mM})$ was perfused for $70 \mathrm{~min}$ through the intestine in vivo, as described previously (Menge et al, 1970), and the rate of disappearance of this substrate was expressed in $\mathrm{mg} / \mathrm{cm}$ intestine $\cdot h$. Glucose concentrations were determined colorimetrically (Hyvärinen and Nikkilä, 1962).

\section{HISTOLOGICAL EXAMINATION}

Following the perfusion the blind loop was excised, cut into segments, $0.5-1.0 \mathrm{~cm}$ in length, fixed for $24 \mathrm{~h}$ in $10 \%$ formalin, embedded in paraffin, cut $(5 \mu)$ and stained with haematoxylin-eosin.

\section{MORPHOMETRIC EVALUATION}

The villus height, crypt length, villus width, and epithelial cell height were measured. Only samples cut parallel to the villus:crypt axis were used for these studies. For each specimen the mean of 20 individual measurements was computed.

\section{ENZYMATIC STUDIES}

The levels of the disaccharidases, lactase, maltase, and sucrase in mucosal homogenates were determined by the method of Dahlqvist (1964). The levels of L-methionyl-glycine, glycyl-L-leucine, L-phenylalanyl-glycine, and L-phenylalanyl-L-proline dipeptidases were also assessed, using the method of Auricchio, Pierro, and Orsatti (1971). The enzyme activities were expressed in terms of the protein content of the mucosal homogenates, which was gauged using the method of Lowry, Rosebrough, Farr, and Randall (1951).

\section{STATISTICAL ANALYSIS}

The results are presented throughout as means \pm SEM. The significance of the difference between the experimental and control series within each group was calculated by means of the Wilcoxon range test, with computation of the probability level, $\alpha$.

\section{Results}

BODY WEIGHT AND FOOD INTAKE

The results pertaining to the animals of group I (infusion of Ringer solution, or of a glucosecontaining medium) are illustrated in figure 1 . The body weight of the animals fell from the day of the operation until the sixth postoperative day, after which it gradually increased. There were never any significant differences. The results for the animals of group II (infusion of Ringer solution, or of a galactose-containing medium) are shown in 

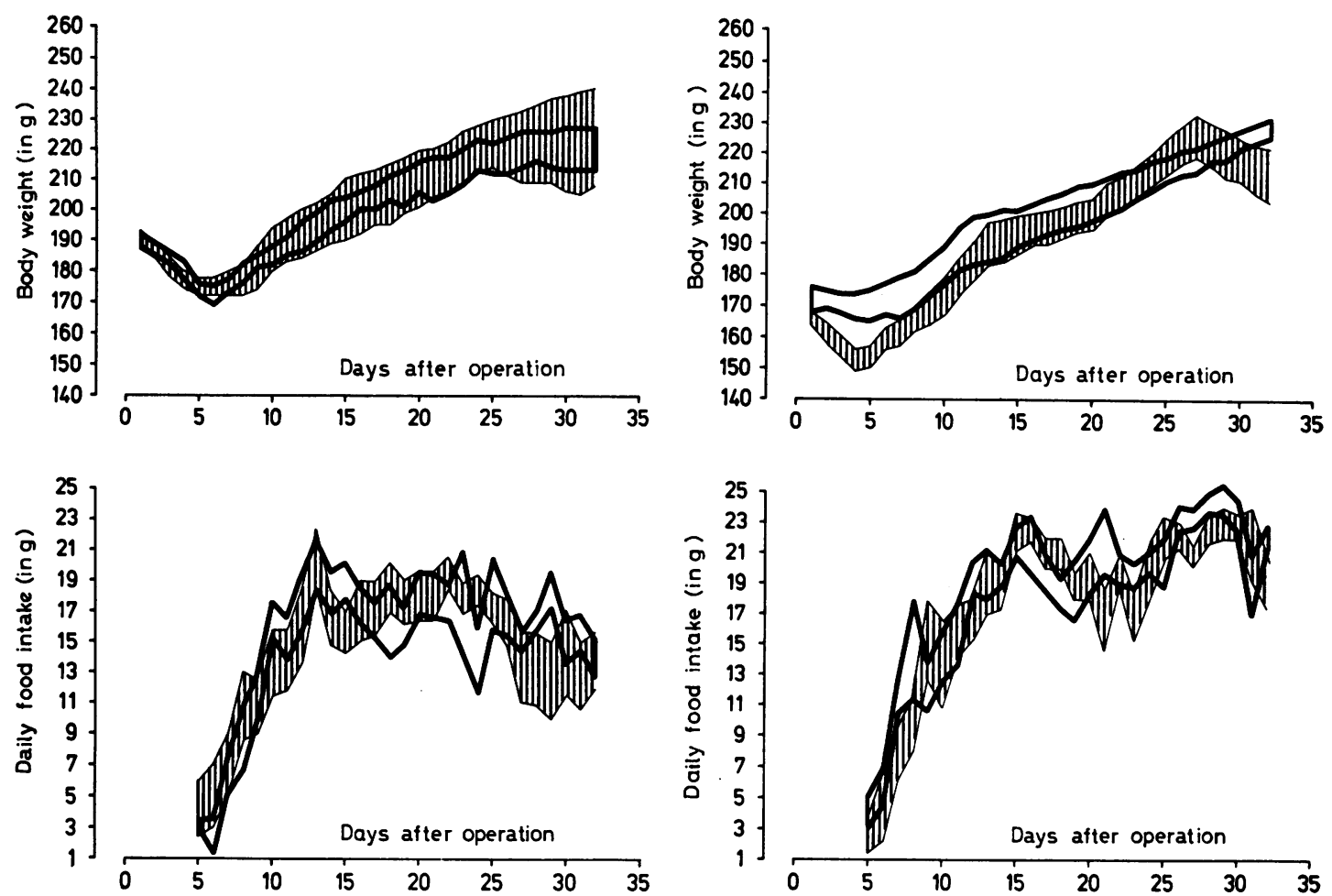

Fig 1

Fig 2

Fig 1 Body weight and daily food intake of the rats infused with Ringer solution or a glucose-containing solution (group I). The space between heavy lines represents means $\pm S E M$ of rats infused with Ringer solution, and the shaded area represents the means $\pm S E M$ of rats infused with glucose-containing medium.

Fig 2 Body weight and food intake of the rats infused with Ringer solution or a galactose-containing solution (group II). Explanation as in figure 1.

fig 2, where it can be seen that only the animals infused with galactose lost weight during the first four days. However, at the end of the experiment, there was no significant difference between the weights of the two series of rats.

Figures 1 and 2 also illustrate the food intake of the animals of the two groups, where a standard pattern of behaviour is revealed in all animals. Following the introduction of solid food on the fifth postoperative day, there was a large daily increase in intake over a period of 10 days, after which the consumption stabilized.

\section{HISTOLOGICAL EXAMINATION}

The blind loops of all animals of group I revealed a normal mucosal structure without any changes in villus shape. The villus height appeared greater in the loops infused with the glucose-containing solution. The cellular content of the lamina propria was normal.
The blind loops of the animals of group II appeared similar whether they were infused with Ringer solution or with a galactose-containing medium.

\section{MORPHOMETRIC ANALYSIS}

There was a significant increase in villus height when glucose was introduced into the blind loops, although there were no differences in villus width, crypt length or epithelial cell height between the various blind loops in group I (table I). The presence of glucose also increased the villus height:crypt length ratio.

In contrast, the blind loops infused with galactose showed a slight but statistically insignificant rise in villus height, and a similar decrease in crypt length (table II). The combination of these two small effects nevertheless led to a significant increase in the villus height-crypt length ratio. The villus width and epithelial cell height were unchanged. 
The nutritive effect of glucose on the structure and function of jejunal self-emptying blind loops in the rat 465

\begin{tabular}{|c|c|c|c|}
\hline \multirow[t]{2}{*}{ Mucosal Structures (in $\mu$ ) } & \multicolumn{2}{|l|}{ Loops Perfused with: } & \multirow{2}{*}{$\begin{array}{l}\text { Probability According to } \\
\text { Wilcoxon Test }\end{array}$} \\
\hline & Ringer Solution $(n=9)$ & Glucose Solution $(n=9)$ & \\
\hline $\begin{array}{l}\text { Villus height } \\
\text { Crypt length } \\
\text { Villus height-crypt length } \\
\text { Villus width } \\
\text { Epithelial cell height }\end{array}$ & $\begin{array}{c}422 \pm 10.9 \\
231 \pm 7.4 \\
1.83 \pm 0.04 \\
99 \pm 2.9 \\
29.6 \pm 0.9\end{array}$ & $\begin{array}{c}488 \pm 18 \cdot 6 \\
231 \pm 9 \cdot 0 \\
2 \cdot 13 \pm 0 \cdot 10 \\
99 \pm 1 \cdot 1 \\
30 \cdot 2 \pm 1 \cdot 3\end{array}$ & $\begin{array}{l}2 a<0.02 \\
2 a>0.05 \\
2 a<0.02 \\
2 a>0.05 \\
2 a>0.05\end{array}$ \\
\hline
\end{tabular}

Table I Morphometric analysis of mucosal structures of self-emptying blind loops of rat jejunum following infusion of Ringer or glucose solution ${ }^{1}$.

${ }^{1}$ Results (in this and subsequent tables) expressed as means \pm SEM of number of samples stated

\begin{tabular}{|c|c|c|c|}
\hline \multirow[t]{2}{*}{ Mucosal Structures (in $\mu$ ) } & \multicolumn{2}{|l|}{ Loops Perfused with: } & \multirow{2}{*}{$\begin{array}{l}\text { Probability According to } \\
\text { Wilcoxon Test }\end{array}$} \\
\hline & Ringer Solution $(n=9)$ & Galactose Solution $(n=10)$ & \\
\hline $\begin{array}{l}\text { Villus height } \\
\text { Crypt length } \\
\text { Villus height:crypt length } \\
\text { Villus width } \\
\text { Epithelial cell height }\end{array}$ & $\begin{array}{c}484 \pm 19.4 \\
216 \pm 10.7 \\
2.28 \pm 0.11 \\
104 \pm 3.3 \\
28.3 \pm 0.9\end{array}$ & $\begin{aligned} 499 & \pm 24.9 \\
192 & \pm 6.4 \\
2.69 & \pm 0.20 \\
98 & \pm 4.7 \\
28.7 & \pm 1.0\end{aligned}$ & $\begin{array}{l}2 a>0.05 \\
2 a>0.05 \\
2 a<0.02 \\
2 a>0.05 \\
2 a>0.05\end{array}$ \\
\hline
\end{tabular}

Table II Morphometric analysis of mucosal structure of self-emptying blind loops of rat jejunum following infusion of Ringer or galactose solution

\begin{tabular}{|c|c|c|c|}
\hline \multirow[t]{2}{*}{ Enzyme } & \multicolumn{2}{|l|}{ Loops Perfused with: } & \multirow{2}{*}{$\begin{array}{l}\text { Probability According to } \\
\text { Wilcoxon Test }\end{array}$} \\
\hline & Ringer Solution $(n=9)$ & Glucose Solution $(n=9)$ & \\
\hline $\begin{array}{l}\text { L-methionyl-glycine-dipeptidase } \\
\text { Glycyl-L-leucine-dipeptidase } \\
\text { L-phenylalanyl-glycine-dipeptidase } \\
\text { L-phenylalanyl-L-proline-dipeptidase }\end{array}$ & $\begin{array}{r}633 \pm 36 \\
3053 \pm 258 \\
247 \pm 7 \\
653 \pm 26\end{array}$ & $\begin{array}{c}619 \pm 57 \\
2664 \pm 320 \\
246 \pm 13 \\
595 \pm 33\end{array}$ & $\begin{array}{l}2 a>0.05 \\
2 a>0.05 \\
2 a>0.05 \\
2 a>0.05\end{array}$ \\
\hline
\end{tabular}

Table III Disaccharidase and dipeptidase activities (U/g protein) in homogenates of the mucosa of self-emptying blind loops of rat jejunum following infusion of Ringer or glucose solution

\begin{tabular}{lccc}
\hline Enzyme & Loops Perfused with: & $\begin{array}{c}\text { Probability According to } \\
\text { Wilcoxon Test }\end{array}$ \\
\cline { 2 - 4 } & Ringer Solution $(n=9)$ & Galactose Solution $(n=10)$ \\
\hline Lactase & $33.6 \pm 0.01$ & $37.0 \pm 4.4$ & $2 a>0.05$ \\
Maltase & $453 \pm 32$ & $453 \pm 24$ & $2 a>0.05$ \\
Sucrase & $155 \pm 10$ & $133 \pm 11$ & $2 a>0.05$ \\
L-methionyl-glycine-dipeptidase & $658 \pm 50$ & $568 \pm 38$ & $2 a>0.05$ \\
Glycyl-L-leucine-dipeptidase & $3421 \pm 423$ & $2545 \pm 254$ & $2 a>0.05$ \\
L-phenylalanyl-glycine-dipeptidase & $244 \pm 13$ & $231 \pm 9$ & $2 a>0.05$ \\
L-phenylalanyl-L-proline-dipeptidase & $666 \pm 40$ & $603 \pm 25$ & $2 a>0.05$ \\
\hline
\end{tabular}

Table IV Disaccharidase and dipeptidase activities (U/g protein) in homogenates of the mucosa of self-emptying blind loops of rat jejunum following infusion of Ringer or galactose solution

\section{ENZYMATIC STUDIES}

The introduction of glucose into the blind loop provoked a marked rise in the maltase activity of mucosal homogenates, though the increases in lactase and sucrase activities were not significant (table III). On the other hand, the dipeptidase levels tended to be reduced in the presence of glucose. 


\begin{tabular}{|c|c|c|c|}
\hline Loops & Absorption (mg. cm intestine ${ }^{-1} \cdot h^{-1}$ ) & No. of Rats & $\begin{array}{l}\text { Probability According to } \\
\text { Wilcoxon Test }\end{array}$ \\
\hline $\begin{array}{l}\text { Group I } \\
\text { Perfused with Ringer solution } \\
\text { Perfused with glucose solution }\end{array}$ & $\begin{array}{l}1 \cdot 64 \pm 0.07 \\
2 \cdot 23 \pm 0 \cdot 10\end{array}$ & $\begin{array}{l}9 \\
9\end{array}$ & $2 a<0.01$ \\
\hline $\begin{array}{l}\text { Group II } \\
\text { Perfused with Ringer solution } \\
\text { Perfused with galactose solution }\end{array}$ & $\begin{array}{l}1 \cdot 76 \pm 0.05 \\
2 \cdot 07 \pm 0 \cdot 13\end{array}$ & $\begin{array}{r}9 \\
10\end{array}$ & $2 a<0.01$ \\
\hline
\end{tabular}

Table $\mathrm{V}$ Glucose transport in vivo in self-emptying blind loops of rat jejunum following infusion of Ringer, glucose, or galactose solutions

Conversely, the introduction of galactose did not cause any significant increase in disaccharidase activities, whilst the tendency to lower dipeptidase levels in the presence of this sugar was greater than in the presence of glucose (table IV).

\section{TRANSPORT STUDIES}

Glucose absorption was considerably greater in self-emptying blind loops that had been previously infused with glucose when compared with the control loops infused simply with Ringer solution (table V). Interestingly, glucose absorption was also increased in the loops that had been infused with galactose, although the influence of galactose is not as great as that of glucose.

\section{Discussion}

The present investigation provides a direct indication that the structure and function of the small intestinal mucosa can be influenced by the presence or absence of a nutrient which can be metabolized. Infusion of the actively transported and readily metabolizable sugar, glucose, into self-emptying blind loops of rat jejunum provokes a notable increase in villus height when compared with similar loops infused with a simple Ringer solution. In order to exclude the possibility that the functional demand of the mucosa might be the factor responsible for this difference, a second series of experiments was carried out, in which galactose was infused in place of glucose. This monosaccharide is transported by the same carrier mechanism as glucose, but is hardly metabolized by the rat jejunal mucosa, so that any nutritive influence of this substrate can be disregarded (Barry, Eggenton, and Smyth, 1969). Since galactose did not elicit a significant increase in villus height, when compared with loops infused with Ringer solution, the inference seems clear that the effect of glucose is occasioned by its metabolism within the epithelial cell, rather than by its transport into it. Furthermore, the morphological differences observed cannot be attributed to changes in growth rate or differences in food intake, since these parameters did not differ from one series to another.

The unchanged crypt length following the instillation of glucose does not, at first sight, appear to be consistent with the increase in villus height. However, Galjaard and Bootsma (1969) demonstrated that a rise in proliferation rate was not necessarily coupled with an increase in crypt length: when the crypt length is unchanged, the zone in which mitosis occurs is extended into the upper third of the crypt. We have also disclosed increased villus height with unchanged crypt length occurring in alloxandiabetic rats, where kinetic studies revealed an increased mitotic rate per crypt (Lorenz-Meyer, Gottesbüren, Menge, Bloch, and Riecken, 1974). The slight reduction in crypt length following galactose infusion, in contrast to the lack of change in this parameter following the instillation of glucose, could indicate that glucose also has a nutritive effect on the crypt epithelium.

The increased maltase activity suggests a specific effect of glucose on the disaccharidase activity of the mucosa, and compares favourably with the substrate-induced stimulation of the activity of these enzymes described under other conditions (Rosensweig and Herman, 1968).

The morphological alterations induced by glucose were accompanied by an increase in the absorptive capacity of the mucosa, as determined by glucose absorption in vivo. Furthermore, a significant rise in glucose absorption was also encountered in the blind loops infused with galactose, despite the absence of morphological changes. This represents one of the few indications of substrate-induced stimulation of transport mechanisms that has been obtained in mammalian systems. The results corroborate those of Fábry, Kujalová, and Petrásek (1959), who studied the morphological and functional changes in rat intestine as a result of hyperphagia under conditions of intermittent starvation. Hypertrophy of the mucosa was induced; this was accompanied by increased glucose absorption only when carbohydrate was included in the diet. Furthermore, our findings correspond with of those 
Scharrer $(1973,1974)$, who observed that the lamb intestine in vitro is able to concentrate both sugars and amino acids, whereas the intestine of the adult sheep was only able to transport amino acids actively, the sugar-transporting system having vanished during maturation of the animal. He attributed his observations to the fact that the small intestine of the sheep receives only small quantities of monosaccharides following development of the forestomach, and therefore the number of transport sites declines in the absence of substrate. The present study discloses the opposite phenomenon, namely, an apparent increase in the number of transport sites for monosaccharides which has been induced by the presence within the experimental loop of a substrate, glucose or galactose, both of which are transported by the same carrier mechanism. The fact that glucose induces a larger increase in transport than galactose may be explained by its simultaneous action on the villus structure, which results in an increase in the surface area of the mucosa as well as an increase in the number of transport carriers. One other explanation for these findings should briefiy be considered, namely, that the increase in glucose disappearance reflects a greater metabolism of this substrate within the enterocyte as opposed to a greater transport rate. This is improbable for two reasons, namely, that the glucose concentration used in the perfusate is probably high enough to saturate the transport mechanism and therefore translocation is the ratelimiting step, or secondly galactose, which also provokes higher transport, is unlikely to induce changes in glucose metabolism in the mucosa.

We are grateful to Dr J. W. L. Robinson (Lausanne) for stimulating criticism and for help with the translation.

References

Auricchio, S., Pierro, M., and Orsatti, M. (1971). Assay of peptidase activities of intestinal brush border membrane with L-amino acid oxidase. Analyt. Biochem., 39, 15-23.

Barry, R. J. C., Eggenton, J., and Smyth, D. H. (1969). Sodium pum ps in the rat small intestine in relation to hexose transfer and metabolism. J. Physiol. (Lond.), 204, 299-310.

Booth, C. C., Evans, K. T., Menzies, T., and Street, D. F. (1959). Intestinal hypertrophy following partial resection of the smal bowel in the tat. Brit. J. Surg., 46, 403-410.

Borgström, B., Dahlqvist, A., Lundh, G., and Sjövall, J. (1957), Studies of intestinal digestion and absorption in the human. J. clin. Invest., 36, 1521-1536.

Dahlqvist, A. (1964). Method for assay of intestinal disaccharidases. Analyt. Biochem., 7, 18-25.

Dowling, R. H., and Booth, C. C. (1967). Structural and functional changes following small intestinal resection in the rat. Clin. Sci., 32, 139-149.

Fábry, P., Kujalová, V., and Petrásek, R. (1959). Einige Folgeerscheinungen der funktionellen und morphologischen Adaptation an geänderte Kalorienzufuhr. Die Nahrung, 3, 642-649.

Galjaard, H., and Bootsma, D. (1969). The regulation of cell proliferation and differentiation in intestinal epithelium. Exp. Cell. Res., 58, 79-92.

Gleeson, M. H., Cullen, J., and Dowling, R. H. (1972). Intestina structure and function after small bowel by-pass in the rat. Clin. Sci., 43, 731-742.

Hyvärinen, A., and Nikkilä, E. A. (1962). Specific determination of blood glucose with o-toluidine. Clin. chim. Acta, 7, 140-143.

Lorenz-Meyer, H., Gottesbüren, H., Menge, H., Bloch, R., and Riecken, E. O. (1974). Intestinal structure and function in relation to blood sugar levels and food intake in experimental diabetes. In Intestinal Adaptation: Proceedings of an International Conference on Anatomy, Physiology and Biochemistry of Intestinal Adaptation, edited by R. H. Dowling and E. O. Riecken, pp. 189-192. Schattauer, Stuttgart and New York.

Lowry, O. H., Rosebrough, N. J., Farr, A. L., and Randall, R. J. (1951). Protein measurement with the Folin phenol reagent. J. biol. Chem. 193, 265-275.

Menge, H., Bloch, R., Lorenz-Meyer, H., and Riecken, E. O. (1973). Morphologie und Funktion isoperistaltischer, ausgeschalteter Jejunalschlingen nach Rückverlegung in die Dünndarmpassage. Res. exp. Med., 161, 133-140.

Menge, H., Bloch, R., Schaumlöffel, E., and Riecken, E. O. (1970). Transportstudien, morphologische, morphometrische und histochemische Untersuchungen zum Verhalten der Dünndarmschleimhaut im operativ ausgeschalteten Jejunalabschnitt der Ratte. Z. ges. exp. Med., 153, 74-90.

Rosensweig, N. S., and Herman, R. H. (1968). Control of jejunal sucrase and maltase activity by dietary sucrose or fructose in man. J. clin. Invest., 47, 2253-2262.

Scharrer, E. (1973). Untersuchungen zur Resorption von D-Glucose und L-Leucin am isolierten Jejunum von Lämmern. $Z h l$. Vet.-Med. [A]., 20, 683-691.

Scharrer, E. (1974). Rückbildung des aktiven intestinalen Glucosetransports beim Wiederkäuer. Z. Tierphysiol., Tierernährg, Futtermittelkde., 32, 320-328. 